\title{
The use of prophylactic single-dose fosfomycin in patients who undergo transrectal ultrasound-guided prostate biopsy: A prospective, randomized, and controlled clinical study
}

\author{
Volkan Sen, MD;' Ozgu Aydogdu, MD;' Ibrahim Halil Bozkurt, MD;' Tarik Yonguc, MD; Pinar Sen, MD; ${ }^{2}$ \\ Salih Polat, MD;' Tansu Degirmenci, MD;' Deniz Bolat, MD'
}

IIzmir Bozyaka Training and Research Hospital Department of Urology, Izmir, Turkey; ${ }^{2}$ zzmir Katip Celebi University Ataturk Training and Research Hospital Department of Infectious Diseases and Clinical Microbiology, lzmir, Turkey

Cite as: Can Urol Assoc J 2015;9(11-12):E863-7. http://dx.doi.org/10.5489/cuaj.3068 Published online December 14, 2015

\section{Abstract}

Introduction: We aimed to demonstrate the efficacy, safety, and convenient use of fosfomycin trometamol in the preoperative antibiotic prophylaxis (PAP) of transrectal ultrasound-guided biopsy of the prostate (TRUSBP) in this prospective, randomized study.

Methods: Between May 2014 and May 2015, a total of 300 patients who underwent TRUSBP were examined prospectively. Patients were randomized into two groups: group 1 consisted of 150 patients who were administered a single dose of $3 \mathrm{~g}$ oral fosfomycin as a PAP the night before the procedure; group 2 consisted of 150 patients who were administered $500 \mathrm{mg}$ oral ciprofloxacin 60 min before the procedure as a PAP. Post-procedural febrile and afebrile infectious complications and pathological characteristics of the two groups were compared prospectively.

Results: The mean age of the patients was $63.5 \pm 0.6$ years in group 1 and $62.9 \pm 0.6$ years in group 2 . A total of two patients $(1.3 \%)$ in group 1 and nine patients $(6.0 \%)$ in group 2 experienced afebrile urinary tract infection (UTI). Afebrile UTI rate was significantly higher in group $2(1.3 \%$ s. $6.0 \%, p=0,032)$. Febrile UTI was detected in two patients in group 2 and one patient in group 1 . Urine cultures revealed $35.7 \%$ fluoroquinolone resistance. As a limitation, although the sample size was appropriate due to the power calculation, we believe that comprehensive studies including larger patient cohorts are needed to support our findings.

Conclusions: Due to its ease-of-use with only a single dose and lower rates of infectious complications (resistant and febrile UTIs), fosfomycin trometamol is a strong alternative for antibiotic prophylaxis in TRUSBP.

\section{Introduction}

The aim of PAP in urological interventions is to prevent infectious complications by decreasing bacterial colonization. However, there is no evidence to support a best choice of antibiotic and prophylactic regimen. Recent stud- ies showed that European urologists differed substantially in their choice of prophylactic antibiotic. ${ }^{1,2}$

Although PAP is widely used in endourological interventions, the benefits of PAP were well-documented only in TRUSBP (level of evidence [LE]: 1b, grading of recommendation [GR]: A) and transurethral prostate resection (TURP) (LE: 1a, GR: A). ${ }^{3}$ PAP is controversial in other endourological interventions, where well-designed, randomized, prospective studies are needed. In low-risk patients, one-day and single-dose PAP is sufficient due to the recommendations in TRUSBP. The most commonly used antibiotics are fluoroquinolones and trimetoprim-sulfamethoxazole (TMP-SMX); however, recent studies pointed to increasing fluoroquinolone resistance. ${ }^{4,5}$

Fluoroquinolone resistance was detected in $35 \%$ of patients admitted to our clinic in the last three years. To prevent infectious complications of TRUSBP, alternative prophylactic regimens, such as fosfomycin (single- or doubledose), were used. ${ }^{6-8}$ Fosfomycin has a broad antibacterial spectrum of activity against the most common Gram-positive (Staphylococcus spp. and streptococci) and Gram-negative (Escherichia coli, Enterobacter spp., Klebsiella spp., Proteus spp., Citrobacter spp.) bacteria. ${ }^{9,10}$ fosfomycin has been widely recommended and used in the management of uncomplicated UTI because of its safety, efficiency, and ease-of-administration. ${ }^{11}$ The rate of resistance against fosfomycin is still low, despite its clinical use for decades, and there is also no cross-resistance or parallel resistance against fosfomycin and other frequently used antibiotics. ${ }^{12,13}$ Therefore, fosfomycin appears to be a good PAP alternative in endourological procedures and TRUSBP.

We aimed to demonstrate the efficacy, safety, and easeof-use of fosfomycin in the PAP of TRUSBP. To the best of our knowledge, this trial represents the first prospective, randomized, controlled study comparing the use of singledose fosfomycin with single-dose $500 \mathrm{mg}$ oral ciprofloxacin in the PAP of TRUSBP. 
Sen et al.

\section{Methods}

This study was done in a tertiary referral centre in Izmir, Turkey, and approved by the hospital ethics committee. All patients were informed and filled in the informed consent form. A total of 300 patients admitted to our clinic for TRUSBP from May 2014 to February 2015 were included in the study. An elevated prostate-specific antigen (PSA) level (>2.5 ng/ml), abnormal digital rectal examination, and previous prostate pathologies (such as high-grade prostate intraepithelial neoplasia [HPIN]) were considered as prostate biopsy indications. The urine tests and urine cultures were clean in all study patients. The patients with a history of UTI, indwelling urinary catheters, and antibiotic use within a month of study initiation were excluded.

Patients were randomly divided into two groups. Randomization was performed using envelopes; a total of 300 envelopes (150 per group) were placed into the box and mixed. The biopsy nurse selected one of the envelopes blindly. Thus patients were randomly selected to use a single dose of $3 \mathrm{~g}$ oral fosfomycin as PAP the night before the procedure (group 1) and $500 \mathrm{mg}$ oral ciprofloxacin 60 min before the procedure (group 2). Gardiner et al assessed serum, urine, and prostatic tissue (transition zone and peripheral zone) fosfomycin concentrations using liquid chromatography tandem mass spectrometry following a single $3 \mathrm{~g}$ oral fosfomycin dose within 17 hours of surgery in healthy men undergoing a transurethral resection of the prostate for $\mathrm{BPH} .^{7}$ Mean overall prostate fosfomycin levels were $6.5 \pm 4.9 \mu \mathrm{g} / \mathrm{g}$ (range, $0.7-22.1 \mu \mathrm{g} / \mathrm{g}$ ) at $602.87(420$ 1046) min after fosfomycin administration, with therapeutic concentrations detectable up to 17 hours following the dose. This is why we preferred to give patients fosfomycin the night before the procedure.

In group 2, we administered $500 \mathrm{mg}$ oral ciprofloxacin 60 min before the procedure as a PAP, according to EAU guideline recommendations. ${ }^{3}$ A fleet enema was self-administered at home by all patients the night before the biopsy. A combined local anesthesia was used as periprostatic nerve block and $2 \%$ lidocaine jelly instilled intrarectally. Biopsy specimens were obtained 15 minutes after the application of local anesthesia. Transrectal ultrasound was performed in lithotomy position by the urologist with a multiplanar, multifrequency probe attached to the BK Medical Flex Focus ultrasound scanner. Prostate volume was calculated with the prostate ellipsoid formula: volume $(\mathrm{V})=0.52(\mathrm{~L} \times \mathrm{W} \times \mathrm{H})$ (L: cephalocaudal diameter; W: width; $\mathrm{H}$ : antero-posterior diameter). In each patient, 12 core biopsy specimens were obtained by an automated biopsy gun with a disposable, 18-gauge biopsy needle. All patients were informed of the possible complications of TRUSBP. Emergency admission to our clinic was recommended when patients developed a fever of $>38.0^{\circ} \mathrm{C}$, severe irritative voiding symptoms, and/or macroscopic hematuria. All patients were asked to attend a follow-up visit in the first week and first month a er biopsy. Physical examination, urine test, and culture were done in follow-up visits.

Afebrile UTI was defined as a fever $<38^{\circ} \mathrm{C}$ and dysuria accompanied by pyuria. ${ }^{6,14}$ Pyuria was defined as the presence of $>10$ white blood cells in $1 \mathrm{~mm}^{3}$ of midstream urine. Febrile UTI was defined as a fever $>38^{\circ} \mathrm{C}$ accompanied by one symptom of the lower urinary tract (i.e., urgency, frequency, dysuria, or suprapubic tenderness), with or without a positive urine culture. ${ }^{6,15}$ Patients with febrile UTI were hospitalized and treated with intravenous antibiotics and antibiotic was switched to an oral form when they were discharged. All patients with afebrile UTI were treated by oral antibiotics due to the culture antibiogram. Post-procedural febrile and afebrile infectious complications and pathological characteristics of two groups were compared prospectively.

Statistical analyses were performed with SPSS version 21.0 (Chicago, IL) statistical software package. Two groups were compared with independent samples t test and chisquare test. Statistical significance was set as a $p$ value of $<0.05$.

\section{Results}

The patient characteristics of both groups are summarized in Table 1. There were no significant differences between the two groups in age and PSA levels.

The pathological results are shown in Table 2. Chronic prostatitis is defined as an increased number of inflammatory cells within the prostatic parenchyma by pathologists. Although chronic prostatitis was found more in group 2 ( $26 \%$ vs. $37 \%)$, it was not statistically significant $(p=0.081)$. A total of two (1.3\%) patients in group 1 and nine $(6.0 \%)$ patients in group 2 experienced afebrile UTI. Afebrile UTI rate was significantly higher in group $2(1.3 \%$ vs. $6.0 \%$,

Table 1. The comparison of patient characteristics and infectious complications of the groups

\begin{tabular}{lccc}
\hline Patient characteristics & Group 1 & Group 2 & $\begin{array}{c}\boldsymbol{p} \text { value } \\
(95 \% \text { Cl) }\end{array}$ \\
\hline Patients (N) & 150 & 150 & \\
Age (years) & $63.5 \pm 7.5$ & $62.9 \pm 7.6$ & $0.50^{*}$ \\
mean \pm SD (range) & $(43-82)$ & $(42-82)$ & $(-1.13-2.29)$ \\
Total PSA (ng/ml) & $12.9 \pm 1.8$ & $12.0 \pm 1.2$ & $0,679^{*}$ \\
mean \pm SE (range) & $(0.6-153)$ & $(1.6-104)$ & $(-3.32-5.09)$ \\
Prostate volume $\left(\mathrm{cm}^{3}\right)$ & $53.1 \pm 22.5$ & $51.3 \pm 24.6$ & $0,544^{*}$ \\
mean \pm SD (range) & $(12-138)$ & $(15-180)$ & $(1.83-2.01)$ \\
Afebrile UTI & $2(1.3 \%)$ & $9(6.0 \%)$ & $0.032^{* *}$ \\
N (\%) & & & \\
Febrile UTI & $1(0.6 \%)$ & $2(1.3 \%)$ & \\
N (\%) & & & \\
\hline
\end{tabular}

*Independent samples t-test; ${ }^{* *}$ Chi-Square test. PSA: prostate-specific antigen; SE: standard error of mean; SD: standard deviation; UTI: urinary tract infection. 
$p=0,032$ ). Febrile UTI was detected in two patients in group 2 and one patient in group 1 . The mean length of hospital stay due to infectious complications was five days in group 1 and seven days in group 2. E. coli was the most common isolated pathogen from urine cultures in all patients $(11 / 14$, $78.6 \%$ ). The other isolated bacteria, K. pneumoniae, was detected in three patients (21.4\%). Urine cultures revealed $35.7 \%$ fluoroquinolone-resistant strains, all of which were extended-spectrum beta-lactamase (ESBL)-producing E.coli and $K$. pneumoniae.

There were no side effects due to the antibiotic regimen in either group. Microbiological characteristics and culture results of patients with afebrile and febrile UTIs are shown in Table 3.

\section{Discussion}

TRUSBP is one of the most common urological interventions worldwide for prostate cancer diagnosis. The complications of TRUSBP are bleeding, pain, infection, lower urinary tract symptoms, urinary retention, erectile dysfunction, and mortality. ${ }^{16}$ Although hematuria and hematospermia are common, they are self-limiting. Severe hematuria, hematospermia, and rectal bleeding are uncommon.

Infectious complications are the most common reason for post-TRUSBP hospitalization. ${ }^{17}$ The incidence of postTRUSBP sepsis was found to be $0.1 \%-5.0 \%$ in the literature. ${ }^{18,19}$ Perioperative antibiotic prophylaxis is widely used to prevent these infectious complications. ${ }^{3}$

Before biopsy, risk factors for PAP should be considered. The risk of post-interventional infectious complications depends on the patient's physical status, the type of urological intervention, surgical field contamination, and the presence of general risk factors, including diabetes mellitus, older age, immune system deficiency, a history of UTI or urogenital infection, indwelling catheters, bacterial burden, and previous instrumentation. ${ }^{3,20}$

Although antibiotic prophylaxis is used to reduce these infectious complications, wide variability in antibiotic choice has been reported. ${ }^{1,2}$ Since fluoroquinolones have a broad spectrum of activity against most Gram-negative organisms and a good prostatic tissue penetration, they are widely used for antibiotic prophylaxis in TRUSBP. However, prolonged use of fluoroquinolones has resulted in increasing microbial resistance; ${ }^{21,22}$ recent years have shown an increase in resistant $E$. Coli. ${ }^{23,24}$ Fluoroquinolone resistance was detected in $35 \%$ of patients admitted to our clinic in the last three years, which is similar to recent reports in TRUSBP. ${ }^{25,26}$ In our study, the overall infectious complication rate was $4 \%$ and the rate of fluoroquinolone resistance was $35.7 \%$. To prevent these infectious complications of TRUSBP, rectal swab cultures should be obtained before the procedure to guide choice of appropriate antibiotics. ${ }^{27}$ Further, alternative
Table 2. The comparison of pathological results of the groups

\begin{tabular}{lccr}
\hline Pathological results & $\begin{array}{c}\text { Group 1 } \\
\text { N=150 }\end{array}$ & $\begin{array}{c}\text { Group 2 } \\
\text { N=150 }\end{array}$ & p value \\
\hline Prostate cancer, N (\%) & $36(24.0 \%)$ & $39(26.0 \%)$ & $0.729^{*}$ \\
Chronic prostatitis, N (\%) & $39(26.0 \%)$ & $56(37.3 \%)$ & $0.081^{*}$ \\
BPH, N (\%) & $45(30.0 \%)$ & $36(24.0 \%)$ & $0.317^{*}$ \\
BPH, N (\%) & $30(20.0 \%)$ & $19(12.7 \%)$ & $0.116^{*}$
\end{tabular}

HPIN, N (\%)

${ }^{*}$ Chi-Square test. BPH: benign prostate hyperplasia; HPIN: high-grade prostatic intraepithelial neoplasia.

prophylactic regimens, such as fosfomycin single- or doubledose have come into use. We used single-dose fosfomycin for PAP of TRUSBP in this study.

Fosfomycin is a phosphonic acid derivative (cis-1,2epoxypropyl phosphonic acid). It acts by inhibiting pyruvyltransferase, a cytoplasmic enzyme that catalyzes the first step in the biosynthesis of peptidoglycans and was initially described and isolated in 1969 from cultures of Streptomyces species. ${ }^{28}$ Fosfomycin has a broad-spectrum activity against Gram-positive and Gram-negative bacteria and was approved for the treatment of uncomplicated UTIs.

Previous studies showed that fosfomycin, administered as a single oral dose, is generally safe and well-tolerated. The most frequent adverse events of fosfomycin are diarrhea, headache, nausea, and abdominal pain. The resistance rates against fosfomycin are still low, despite its clinical use; therefore, fosfomycin could also be recommended in endourological procedures if PAP is indicated. ${ }^{11}$ Gardiner et al prospectively assessed the penetration of fosfomycin into benign prostatic tissue in a large cohort of otherwise healthy men undergoing TURP. ${ }^{7}$ They detected that oral fosfomycin achieved sufficient concentrations in most cases and pointed out that fosfomycin may be a potential option for prophylaxis pre-TRUSBP and possibly for the treatment of multidrug-resistant Gram-negative bacterial prostatitis.

There are few reports about the use fosfomycin as a PAP in TRUSBP. Ongun et al compared single-dose fosfomycin with single-dose levofloxacin and $500 \mathrm{mg}$ oral ciprofloxacin twice daily administered for five days starting one day before the procedure in a retrospective study and Lista et al compared double doses of fosfomycin with $500 \mathrm{mg}$ oral ciprofloxacin twice daily administered for five days starting one day before the procedure in a prospective randomized study. ${ }^{6-8}$ Fosfomycin was found to be as safe and as effective as ciprofloxacin and levofloxacin in these two studies.

As far as we know, our study represents the first prospective, randomized, controlled study comparing single-dose fosfomycin with single-dose $500 \mathrm{mg}$ oral ciprofloxacin in the PAP of TRUSBP. In the present study, febrile UTI was observed in only one patient and afebrile UTI was detected in two patients in the fosfomycin group. Afebrile UTI rate 
Sen et al.

\begin{tabular}{lcc}
\hline Table 3. Microbiological characteristics and culture results of patients with afebrile and febrile UTls (N=14/300, 4.7\%) & Fosfomycin \\
\hline & Ciprofloxacin & $3 / 150(2.0 \%)$ \\
\hline Patients (N) & $11 / 150(7.3 \%)$ & 2 \\
Afebrile UTI (N) & 9 & 2 \\
Fluoroquinolone-sensitive E. Coli/ K. Pneumoniae & 6 & - \\
Fluoroquinolone-resistant E. Coli /K. Pneumoniae & 3 & 1 \\
Febrile UTI (N) & 2 & 1 \\
Fluoroquinolone-sensitive E. Coli/ K. Pneumoniae & - & - \\
Fluoroquinolone-resistant E. Coli /K. Pneumoniae & 2 & - \\
ESBL E. Coli* & - & \\
\hline *Also fluoroquinolone-resistant. ESBL: extended-spectrum beta-lactamases; UTI: urinary tract infection. &
\end{tabular}

was significantly higher in the ciprofloxacin group.

Our results revealed that single-dose fosfomycin is as effective and as safe as single-dose $500 \mathrm{mg}$ oral ciprofloxacin in the antibiotic prophylaxis for prostate biopsy. The main advantages of fosfomycin includes its simple oral use as single dose and lower cost compared to intravenous antibiotic prophylaxis regimens.

\section{Conclusions}

Its ease-of-use (single dose) and lower rates of infectious complications, including resistant and febrile UTIs, makes fosfomycin a strong alternative for antibiotic prophylaxis in TRUSBP. Further studies with larger sample size are required to support the findings of this study.

Competing interests: The authors declare no competing financial or personal interests.

This paper has been peer-reviewed.

\section{References}

1. Grabe M. Perioperative antibiotic prophylaxis in urology. Curr Opin Urol 2001;11:81-5. http://dx.doi. org/10.1097/00042307-200101000-00012

2. Wilson NI, Lewis HJ. Survey of antibiotic prophylaxis in British urological practice. Br J Urol 1985;57:47882. http://dx.doi.org/10.1111/i.1464-410X.1985.tb06316.x

3. Grabe M, Bartoletti R, Bijerklund-Johansen TE, et al. Guidelines on urological infections. EAU 2015 guidelines. http://uroweb.org/wp-content/uploads/19-Urological-infections_LR2.pdf. Accessed Dec. 3, 2015

4. Wagenlehner FM, van Ostrum E, Tenke $P$, et al. Infective complications after prostate biopsy: Outcome of the Global Prevalence Study of Infections in Urology (GPIU) 2010 and 2011, A prospective Multinational Multicentre Prostate Biopsy Study. Eur Urol 2013;63:521-7. http://dx.doi.org/10.1016/i.eururo.2012.06.003

5. Taylor AK, Zembower TR, Nadler RB, et al. Targeted antimicrobial prophylaxis using rectal swab cultures in men undergoing transrectal ultrasound guided prostate biopsy is associated with reduced incidence of postoperative infectious complications and cost of care. J Urol 2012;187:1275-9. http://dx.doi. org/10.1016/i.juro.2011.11.115

6. Ongün $S$, Aslan $G$, Avkan-Oguz V. The effectiveness of single-dose fosfomycin as antimicrobial prophylaxis for patients undergoing transrectal ultrasound-guided biopsy of the prostate. Urol Int 2012;89:439-44. http://dx.doi.org/10.1159/000342370

7. Gardiner BJ, Mahony AA, Ellis AG, et al. Is fosfomycin a potential treatment alternative for multidrugresistant Gram-negative prostatitis? Clin Infect Dis 2014;58:e101-05. http://dx.doi.org/10.1093/ cid/cit704
8. Lista F, Redondo C, Meilán E, et al. Efficacy and safety of fosfomycin-trometamol in the prophylaxis for transrectal prostate biopsy. Prospective randomized comparison with ciprofloxacin. Actas Urol Esp 2014;38:391-6. http://dx.doi.org/10.1016/j.acuro.2014.01.002

9. Falagas ME, Kastoris AC, Kapaskelis AM, et al. Fosfomycin for the treatment of multidrug-resistant, including extended spectrum beta-lactamase producing Enterobacteriaceae infections: A systematic review. Lancet Infect Dis 2010;10:43-50. http://dx.doi.org/10.1016/S1473-3099(09)70325-1

10. Oteo J, Bautista V, Lara $\mathrm{N}$, et al. Parallel increase in community use of fosfomycin and resistance to fosfomycin in extended-spectrum betalactamase (ESBL)-producing Escherichia coli. J Antimicrob Chemother 2010; 65:2459-63. http://dx.doi.org/10.1093/jac/dkq346

11. Falagas ME, Giannopoulou KP, Kokolakis GN, et al. Fosfomycin: Use beyond urinary tract and gastrointestinal infections. Clin Infect Dis 2008;46:1069-77. http://dx.doi.org/10.1086/527442

12. Gupta $\mathrm{K}$, Hooton $T M$, Naber KG, et al. International clinical practice guidelines for the treatment of acute uncomplicated cystitis and pyelonephritis in women: a 2010 update by the Infectious Diseases Society of America and the European Society for Microbiology and Infectious Diseases. Clin Infect Dis 2011; 52 : e103-20. http://dx.doi.org/10.1093/cid/ciq257

13. Naber KG, Schito G, Botto H, et al. Surveillance study in Europe and Brazil on clinical aspects and Antimicrobial Resistance Epidemiology in Females with Cystitis (ARESC): Implications for empiric therapy. Eur Urol 2008;54:1164-75. http://dx.doi.org/10.1016/i.eururo.2008.05.010

14. Whittam BM, Thomasch JR, Makari JH, et al. Febrile urinary tract infection after ureteroneocystostomy: A contemporary assessment at a single institution. J Urol 2010; 183: 688-92. http://dx.doi. org/10.1016/i.juro.2009.10.039

15. Chiang BJ, Pu YS, Chung SD, et al. Quinolone prophylaxis in transrectal ultrasound guided prostate biopsy: An eight-year single center experience. Scientific World Journal 2013;2013:452107. http:// dx.doi.org/10.1155/2013/452107

16. Loeb S, Vellekoop A, Ahmed HU, et al. Systematic review of complications of prostate biopsy. Eur Urol 2013;64:876-92. http://dx.doi.org/10.1016/i.eururo.2013.05.049

17. Zani EL, Clark OA, Rodrigues Netto N Jr. Antibiotic prophylaxis for transrectal prostate biopsy. Cochrane Database Syst Rev 2011;5:CD006576. http://dx.doi.org/10.1002/14651858.cd006576.pub2

18. Carigan A, Roussy JF, Lapointe V, et al. Increasing risk of infectious complications after transrectal ultrasound-guided prostate biopsies: Time to reassess antibacterial prophylaxis? Eur Urol 2012;62:453-9. http://dx.doi.org/10.1016/i.eururo.2012.04.044

19. Nam RK, Saskin R, Lee $Y$, et al. Increasing hospital admission rates for urological complications after transrectal ultrasound guided prostate biopsy. J Urol 2010;183:963-8. http://dx.doi.org/10.1016/i. juro.2009.11.043

20. Mangram AJ, Horan TC, Pearson ML, et al. Guideline for prevention of surgical site infection, 1999. Centers for Disease Control and Prevention (CDC) Hospital Infection Control Practices Advisory Committee. Am J Infect Control 1999;27:97-132. http://dx.doi.org/10.1016/S0196-6553(99)70088-X

21. Carmignani L, Picozzi S, Spinelli M, et al. Bacterial sepsis following prostatic biopsy. Int Urol Nephrol 2012;44:1055-63. http://dx.doi.org/10.1007/s11255-012-0145-9

22. Williamson $D A$, Barrett $L K$, Rogers $B A$, et al. Infectious complications following transrectal ultrasoundguided prostate biopsy: New challenges in the era of multidrug-resistant Escherichia coli. Clin Infect Dis 2013:57:267-74. http://dx.doi.org/10.1093/cid/cit193

23. Zervos MJ, Hershberger E, Nicolau DP, et al. Relationship between fluoroquinolone use and changes in susceptibility to fluoroquinolones of selected pathogens in 10 U.S. teaching hospitals, 1991-2000. Clin Infect Dis 2003;37:1643-8. http://dx.doi.org/10.1086/379709

24. Binsaleh $S$, Al-Assiri M, Aronson $S$, et al. Septic shock after transrectal ultrasound guided prostate biopsy. Is ciprofloxacin prophylaxis always protecting? Can I Urol 2004;11:2352-3.

25. Feliciano $J$, Teper $E$, Ferrandino $M$, et al. The incidence of fluoroquinolone resistant infections after prostate biopsy-are fluoroquinolones still effective prophylaxis? J Urol 2008; 179:952-5. http://dx.doi. org/10.1016/i.juro.2007.10.071 
26. Hori S, Sengupta A, Joannides A, et al. Changing antibiotic prophylaxis for transrectal ultrasound-guided prostate biopsies: Are we putting our patients at risk? BJU Int 2010;106:1298-302. http://dx.doi. org/10.1111/j.1464-410X.2010.09416.X

27. Liss MA, Chang A, Santos R, et al. Prevalence and significance of fluoroquinolone resistant Escherichia coli in patients undergoing transrectal ultrasound guided prostate needle biopsy. J Urol 2011;185:1283-8. http://dx.doi.org/10.1016/i.juro.2010.11.088
28. Hendlin D, Stapley E0, Jackson $M$, et al. Phosphonomycin, a new antibiotic produced by strains of streptomyces. Science 1969;166:122-3. http://dx.doi.org/10.1126/science.166.3901.122

Correspondence: Dr. Volkan Sen, Izmir Bozyaka Training and Research Hospital, Department of Urology, Izmir, Turkey; T. + 90-553-389 68 59; F.+90-232-41234 99; sen_volkan@yahoo.com 